\title{
Uncertainty Quantification of Cooling Load Calculation
}

\author{
Da Lin, Dazhou Zhao \\ Huadian Electric Power Research Institute Co., LTD, Hangzhou, China \\ E-mail:da-lin@chder.com,dazhou-zhao@chder.com
}

Keywords:uncertainty quantification; cooling load; Monte Carlo simulation

Abstract: Cooling load calculation is commonly implemented with building energy simulation software among HVAC industry. While those software have limited ability to handle large amount of uncertain input data. Since they can only accept deterministic or scenario input data. In this paper, a new model is proposed to calculate the cooling load. The uncertainty of input data is considered and Monte Carlo simulation is used to calculate the building cooling load.

\section{Introduction}

Cooling load calculation is basis of HVAC system design, as HVAC system equipment selection is mainly depend on accurate quantification of building cooling load. Energy model and reliable input parameter are two important factors affect the accuracy of the cooling load prediction. Nowadays the energy model in most of the commercial software such as EnergyPlus, DeST and DOE-2 has matured over the past decades ${ }^{[1]}$. All those software use constants input parameter, such as occupants' density, equipment heat gain or even weather data. But the uncertainty arises from those parameters is inevitable. For early design stage, because lacking knowledge about feature of building and operation schedule. Large number of parameters cannot be determined. On the other hand, the uncertainty behind some parameters are hardly to eliminate even under later design stage, since detailed measurement of those parameter is time consuming and costly. Machine learning or data mining have been implemented to predict the uncertainty input parameters or even to predict the total building cooling load. Limitation of this method is large number of history data required.

In this paper, a mathematical model for uncertainty cooling load calculation has been developed. The probability distributions of uncertainty parameters have been quantified. Finally, a real case cooling load has been calculated using uncertainty method.

\section{Model}

\subsection{Model Overview}

The cooling load calculation model is implemented with Monte Carlo simulation to quantify the uncertainty. Input parameter can be classified as two categories: deterministic parameter, uncertain parameter. The value of deterministic parameter and probability distribution of uncertain parameter would be varied as change of scenario. Monte Carlo simulations sample from a probability distribution for each parameter to produce enough possible outcomes. Finally, the cooling load 
probability distribution can be plotted. The whole process has been calculated by Matlab code. The detailed mathematical model is explained in the following two sections.

\subsection{Solar Radiation Model}

In this section, a solar radiation model is developed mainly based on clear sky model and Liu, Jordan deduction ${ }^{[2]}$. Solar gain is an important factor effecting the building cooling load. The variation of solar gain would significantly alter the building cooling load. So, an accurate solar radiation model would be essential for building cooling load calculation.

Solar radiation can be divided into three components: beam irradiation, diffused radiation, and reflected radiation. Normally any exterior surfaces of building can be categorized as two areas: sunlit area, shading area. Sunlit area will calculate total three components. Shading area will calculate last two components, since there is no beam irradiation on shading surface. For simplicity the reflected radiation is not taken into consideration. Therefore, the total insolation intensity on the titled surface would be calculated through Eq. (1)-(7). Where the solar constant $I_{S C}=1367 \mathrm{~W} / \mathrm{m}^{2} . \tau_{b}$ is beam transmittance which change with variation of time and location. In this paper, $\tau_{b}$ is 0.620 for time $12: 00^{[3]}$.

$$
\begin{gathered}
\mathrm{I}_{\mathrm{t}}=\mathrm{I}_{\mathrm{b}} \mathrm{R}_{\mathrm{b}}+\mathrm{I}_{\mathrm{d}} \mathrm{R}_{\mathrm{d}} \#(1) \\
\mathrm{I}_{\mathrm{b}}=I_{0 h} \tau_{b} \#(2) \\
\mathrm{I}_{\mathrm{d}}=I_{0 h} \tau_{d} \#(3) \\
\tau_{d}=0.271-0.294 \tau_{b} \#(4) \\
\mathrm{R}_{\mathrm{b}}=\frac{\cos \theta_{i}}{\cos \theta_{z}} \#(5) \\
\mathrm{R}_{\mathrm{d}}=\frac{1+\cos \beta}{2} \#(6) \\
I_{0 h}=I_{S C}\left[1+0.034 \cos \left(2 \pi \frac{n}{365.25}\right)\right] \cos \theta_{z} \#(7)
\end{gathered}
$$

Detailed solar angle calculation is based on the following assumption: $\mathrm{n}=1$ on the 1st January; Vernal equinox day is 20th March, $\mathrm{n}=79, \delta=0$; Summer Solstice day is 21st June, $\mathrm{n}=172, \delta=$ 23.45; Autumnal Equinox day is 23rd September, $\mathrm{n}=266, \delta=0$; Winter Solstice day is 21st December, $\mathrm{n}=355, \delta=-23.45$. The solar angle is calculated through Eq. (8)-(11).

$$
\begin{aligned}
\cos \theta_{i}= & \sin \delta \sin \Phi \cos \beta+\sin \delta \cos \Phi \sin \beta \cos A_{Z S} \\
& +\cos \delta \cos \Phi \cos \beta \cos \omega \\
& -\cos \delta \sin \Phi \sin \beta \cos A_{Z S} \cos \omega \\
& -\cos \delta \sin \beta \sin A_{Z S} \sin \omega \#(8) \\
\delta= & 23.45 \frac{\pi}{180} \sin \left[2 \pi\left(\frac{284+n}{365.25}\right)\right] \#(9)
\end{aligned}
$$

For simplicity, only vertical walls and horizontal roofs are taken into consideration.

For vertical wall, $\beta=\pi / 2$, then there is Equation (10).

$$
\begin{gathered}
\cos \theta_{i}=\sin \delta \cos \Phi \cos A_{Z S}-\cos \delta \sin \Phi \cos A_{Z S} \cos \omega \\
-\cos \delta \sin A_{Z S} \sin \omega \#(10)
\end{gathered}
$$

For horizontal roof, $\beta=0$, then there is Equation (11). 
$\cos \theta_{i}=\sin \delta \sin \Phi+\cos \delta \cos \Phi \cos \omega \#(11)$

Table 1 Nomenclature for solar radiation model

\begin{tabular}{|c|l|}
\hline$\delta$ & Declination angle \\
\hline$\theta_{Z}$ & Zenith angle \\
\hline$\alpha$ & Altitude angle \\
\hline$\omega$ & Hour angle \\
\hline$\beta$ & Surface inclination angle \\
\hline$A_{Z S}$ & Surface azimuth angle \\
\hline$\Phi$ & Latitude \\
\hline$n$ & Number of day \\
\hline$\theta_{i}$ & Incidence Angle \\
\hline $\mathrm{I}_{\mathrm{t}}$ & Total insolation intensity \\
\hline $\mathrm{I}_{\mathrm{b}}$ & Beam irradiation intensity \\
\hline $\mathrm{I}_{\mathrm{d}}$ & Diffused radiation intensity \\
\hline$I_{0 h}$ & Extraterrestrial insolation \\
\hline$I_{S C}$ & Solar constant \\
\hline$\tau_{b}$ & Beam transmittance \\
\hline$\tau_{d}$ & Diffuse transmittance \\
\hline $\mathrm{R}_{\mathrm{b}}$ & Beam correction factor \\
\hline $\mathrm{R}_{\mathrm{d}}$ & Diffuse correction factor \\
\hline
\end{tabular}

\subsection{Building Energy Model}

Figure 1 illustrates the building energy model. This paper uses this model to calculate the sensible cooling load. The total sensible cooling load mainly consist of seven parts: exterior wall conductive heat flow, window conductive heat flow, roof conductive heat flow, solar heat through window, total internal gain, ventilation heat gain, infiltration heat gain.

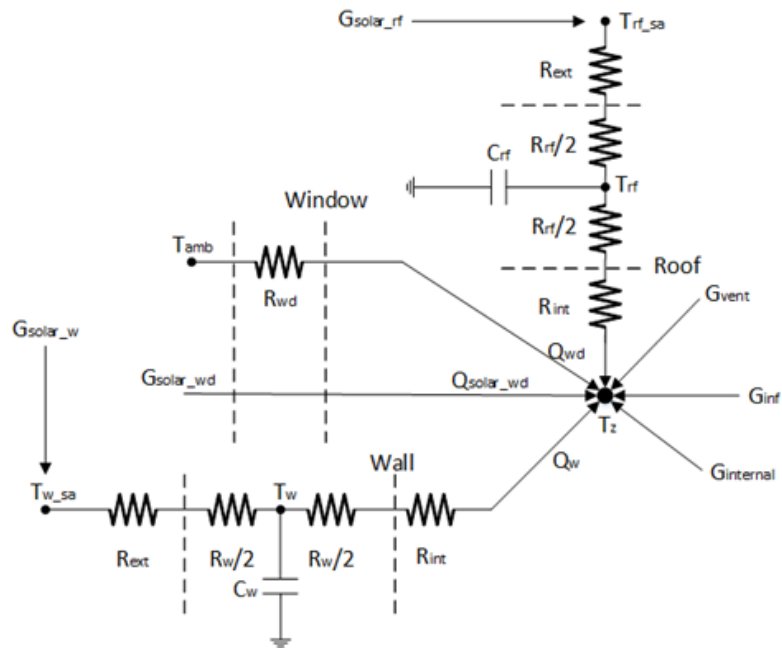

Figure 1 Illustration of the building energy model

The external wall would neglect the difference of each layer. So, model use only one overall thermal resistance and one overall thermal capacitance to describe the wall. The roofs of the building in this model are based on similar assumption. 4th order Runge-Kutta method is used to solve the 
wall temperature and roof temperature differential equation. Heat gain through wall is calculated through Eq. (12)-(17) Since each room has same design temperature. Model assumes that there is no heat transfer between different rooms.

$$
\begin{gathered}
\mathrm{SCL}=\sum_{1}^{n} \mathrm{Q}_{w n}+\sum_{1}^{n} \mathrm{Q}_{w d n}+\sum_{1}^{n} \mathrm{Q}_{\text {roofn }}+\sum_{1}^{n} \mathrm{Q}_{\text {solar }, w d n} \\
+\mathrm{G}_{\text {internal }}+\mathrm{G}_{\text {vent }}+\mathrm{G}_{\text {inf }} \#(12) \\
\mathrm{Q}_{w n}=\frac{T_{w n}-T_{d}}{R_{w, i n t}} \#(13) \\
C_{w} \frac{d T_{w n}}{d t}=\frac{T_{s a}-T_{w n}}{R_{w, e x t}}-\frac{T_{d}-T_{w n}}{R_{w, i n t}} \#(14) \\
T_{s a}=T_{a m b}+\frac{G_{T} \alpha_{\text {ext }}}{h_{\text {ext }}} \#(15) \\
R_{w, \text { ext }}=R_{\text {ext }}+0.5 R_{w}=\frac{1}{h_{\text {ext }} A_{w n}}+\frac{0.5 t_{w n}}{h_{w} A_{w n}} \#(16) \\
R_{w, \text { int }}=0.5 R_{w}=\frac{0.5 t_{w n}}{h_{w} A_{w n}} \#(17) \\
\mathrm{Q}_{w d n}=\mathrm{U}_{w d} \mathrm{~A}_{w d n}\left(T_{a m b}-T_{d}\right) \#(18) \\
\mathrm{Q}_{\text {solar,wdn }}=S H G C \cdot A_{w d} \cdot G_{T} \#(19) \\
\mathrm{G}_{\text {internal }}=\mathrm{G}_{\text {equip }}+\mathrm{G}_{\text {light }}+\mathrm{G}_{\text {occupants }} \#(20) \\
\mathrm{G}_{v e n t}=\dot{m}_{v e n t} \mathrm{c}_{p}\left(T_{a m b}-T_{d}\right) \#(21) \\
\mathrm{G}_{\text {inf }}=\dot{m}_{\text {inf }} \mathrm{c}_{p}\left(T_{a m b}-T_{d}\right) \#(22)
\end{gathered}
$$

\section{Case Calculation}

\subsection{Case Overview}

The case calculation assumes that all input parameters are acquired under early design stage. The calculation object is the office building which located in Wuhan creative world. Figure 2 shows the geometry of the object building. The more detailed design information of this building would explain in the next section. Southern side wall of building marks as wall_1, eastern side wall marks as wall_2, northern side wall marks as wall_3, western side wall marks as wall_4, roof marks as wall_5. Detailed building geometry which has no significant effect on cooling load calculation is neglect in order to simplify the calculation. 

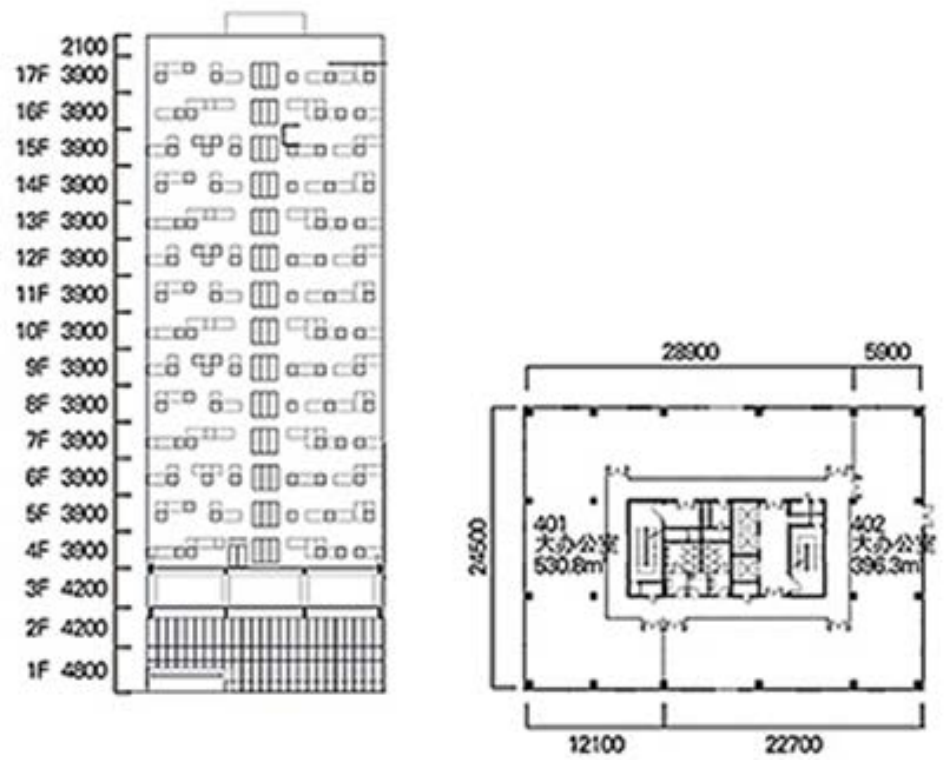

Figure 2 The geometry of the object building

The solar gain is calculated for each wall and roof of the building. The cooling load is calculated hourly. In this paper only 12:00 uncertainty cooling load is calculated.

\subsection{Input Parameter}

In this section both deterministic input parameters and uncertainty input parameter would be explained and listed detailed.

Detailed deterministic input parameters are listed in Table 2 below which has not included building geometry parameter. Each wall has identical thickness and use the same material. Those parameters can be figure out from Figure 2.

Table 2 Detailed deterministic input parameters

\begin{tabular}{|l|l|l|}
\hline$\Phi$ & $30^{\circ}$ & Latitude \\
\hline $\mathrm{n}$ & 166 & Number of day \\
\hline$A_{Z S}$ & $0^{\circ}$ & Building Azimuth \\
\hline$t_{w}$ & 0.3 & Wall thickness $(\mathrm{m})$ \\
\hline $\mathrm{c}_{p}$ & 1030 & Air specific heat $(\mathrm{J} / \mathrm{kg} \mathrm{K})$ \\
\hline$\rho_{\text {air }}$ & 1.16 & Air density $(\mathrm{kg} / \mathrm{m} 3)$ \\
\hline$T_{d}$ & 25 & Room design temperature $\left({ }^{\circ} \mathrm{C}\right)$ \\
\hline$V_{r}$ & 59596.74 & Room volume $(\mathrm{m} 3)$ \\
\hline$\rho_{\text {people }}$ & 10 & Occupancy density (m2/person) \\
\hline
\end{tabular}

The uncertainty input parameters are listed in table 3. The uncertainty input parameters can be divided into two types in this paper base on their probability distribution. They are uniform distribution which described by function $\mathrm{U}(a, b)$ and triangular distribution which described by function $\mathrm{T}(a, c, b)$. "a” is lower limit of probability distribution. "b" is upper limit of probability distribution. "c" is highest probable value. Each of two types of probability distribution would be shown in Figure 3 from selected example. 
Table 3 The uncertainty input parameters

\begin{tabular}{|l|l|l|}
\hline $\mathrm{U}_{\text {wd }}$ & $\mathrm{T}(4.2,4.8,5.6)$ & $\begin{array}{l}\text { Window thermal transmittance } \\
(\mathrm{W} / \mathrm{m} 2 \mathrm{~K})\end{array}$ \\
\hline$h_{\text {ext }}$ & $\mathrm{U}(11,26)$ & $\begin{array}{l}\text { Average heat transfer coefficient on } \\
\text { external wall }(\mathrm{W} / \mathrm{m} 2 \mathrm{~K})\end{array}$ \\
\hline$h_{\text {int }}$ & $\mathrm{U}(7.9,8.4)$ & $\begin{array}{l}\text { Average heat transfer coefficient on } \\
\text { internal wall }(\mathrm{W} / \mathrm{m} 2 \mathrm{~K})\end{array}$ \\
\hline $\mathrm{C}_{\mathrm{w}} / \mathrm{A}_{\mathrm{w}}$ & $\mathrm{T}(652,686,720)$ & $\begin{array}{l}\text { Heat capacitance of wall per area } \\
\text { (kJ/K m3) }\end{array}$ \\
\hline SHGC & $\mathrm{U}(0.38,0.48)$ & Solar heat to gain coefficient \\
\hline$\alpha_{\text {ext }}$ & $\mathrm{T}(0.36,0.56,0.7)$ & Absorptivity of the exterior wall \\
\hline $\mathrm{V}_{\text {vent }}$ & $\mathrm{T}(24,30,36)$ & Ventilation $(\mathrm{m} 3 /$ person $\mathrm{h})$ \\
\hline $\mathrm{n}_{\text {inf }}$ & $\mathrm{U}(0.5,1)$ & Infiltration (air change/h) \\
\hline $\mathrm{G}_{\text {light }}$ & $\mathrm{T}(6,9,13)$ & Lighting gains $(\mathrm{W} / \mathrm{m} 2)$ \\
\hline $\mathrm{G}_{\text {equip }}$ & $\mathrm{T}(10,13,18)$ & Equipment gains $(\mathrm{W} / \mathrm{m} 2)$ \\
\hline $\mathrm{G}_{\text {occup }}$ & $\mathrm{T}(4,6,9)$ & Occupants sensible gain $(\mathrm{W} / \mathrm{m} 2)$ \\
\hline
\end{tabular}

Figure 3 illustrate frequency histogram and scatter plot of equipment gains which is sample from triangular probability distribution. The total sample number is five thousand. This triangular probability distribution is range from $10 \mathrm{~W} / \mathrm{m} 2$ to $18 \mathrm{~W} / \mathrm{m} 2$, the peak probable value is $13 \mathrm{~W} / \mathrm{m} 2$. Figure4 illustrate frequency histogram and scatter plot of SHGC which is sample from uniform probability distribution. The total sample number is five thousand. This uniform probability distribution is range from 0.38 to 0.48 .
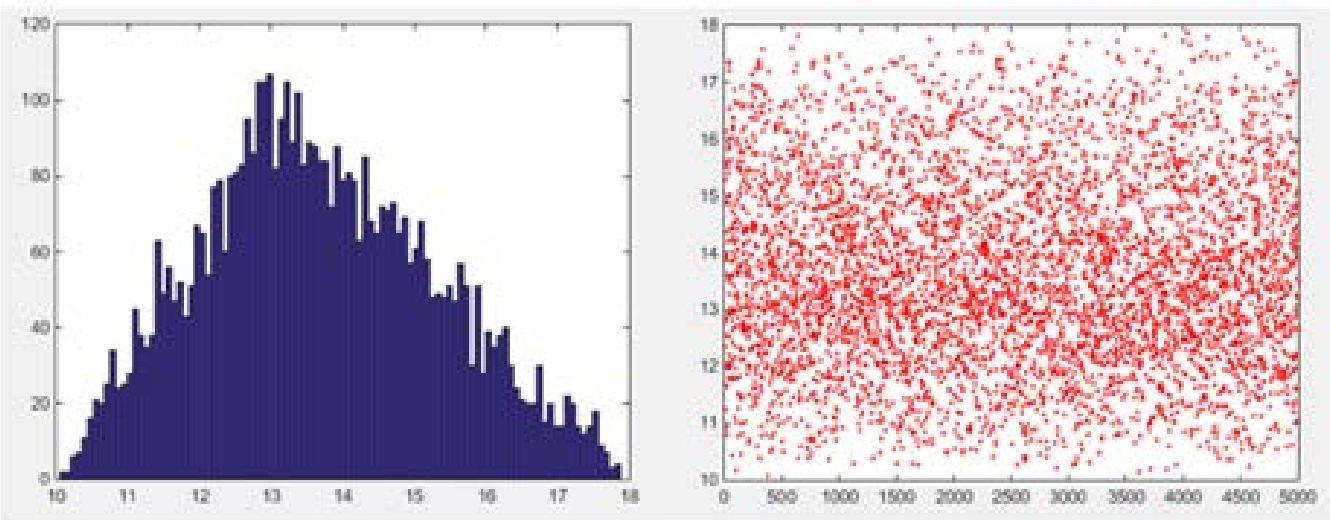

Figure 3 Illustration of frequency histogram scatter plot of equipment gains
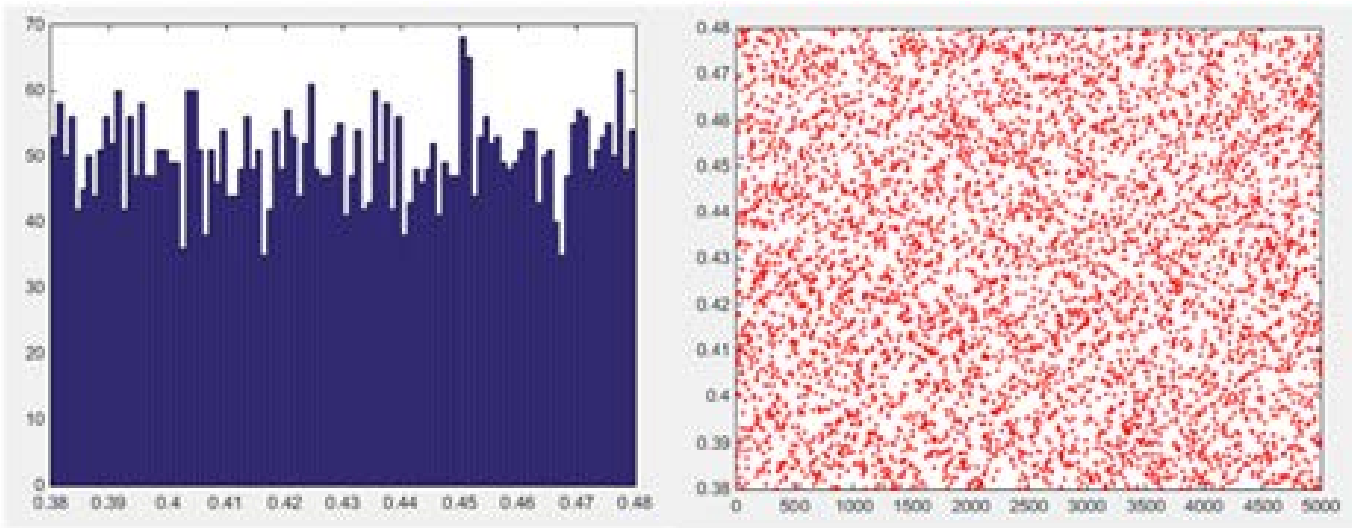

Figure 4 Illustration of frequency histogram and scatter plot of SHGC 


\section{Result and Discussion}

The uncertainty result is calculated using Monte Carlo simulation. The total random sample is ten thousand under the consideration of calculation time. If we plot from larger random sample, the result would be closer to the standard normal distribution line. Figure 5 shows frequency histogram of cooling load distribution. The vertical axis represents the frequency number for each possible cooling load. The horizontal axis represents possible cooling load. It reveals the uncertainty cooling load is normal distribution which is ranging from $0.85 \mathrm{Mw}$ to $1.3 \mathrm{Mw}$. The frequency peak is located at $1.07 \mathrm{Mw}$ cooling load.

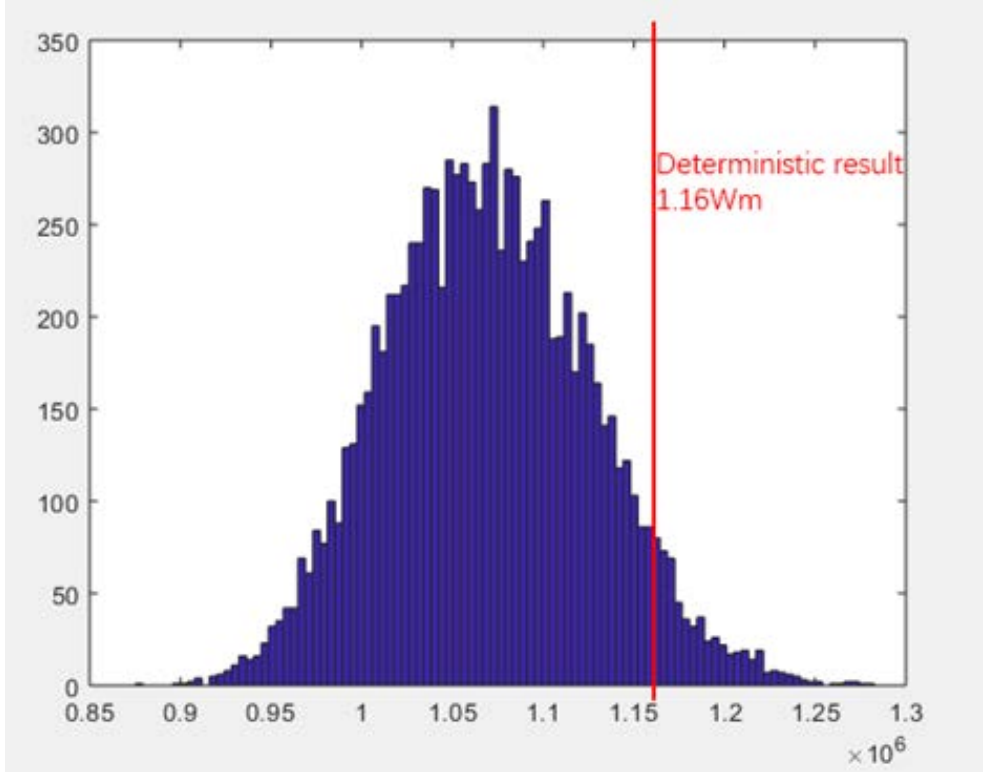

Figure 5 Frequency histogram of cooling load distribution

The uncertainty result is compared with deterministic result which calculated by commercial building energy software. The deterministic result which is $1.16 \mathrm{Mw}$ locates at right hand side of peak frequency cooling load. Figure 5 shows the deterministic result normally can't represent the peak cooling load. Meanwhile deterministic result cannot provide enough information for underload design or overload design compared with uncertainty result.

\section{References}

[1] Zhu, et al. "A detailed loads comparison of three building energy modeling programs: EnergyPlus, DeST and DOE2.1E." Building Simulation 6.3(2013):323-335.

[2] Liu, Benjamin Y. H., and R. C. Jordan. "The interrelationship and characteristic distribution of direct, diffuse and total solar radiation." Solar Energy 4.3(1960):1-19.

[3] Duffie, John A, Beckman, William A, and McGowan, Jon. "Solar Engineering of Thermal Processes." A WileyInterscience Publication 116.1(2006):549.

[4] Haarhoff, J., and E. H. Mathews. "A Monte Carlo method for thermal building simulation." Energy \& Buildings 38.12(2006):1395-1399.

[5] Mavromatidis, Georgios, K. Orehounig, and J. Carmeliet. "A review of uncertainty characterisation approaches for the optimal design of distributed energy systems." Renewable \& Sustainable Energy Reviews 88(2018):258-277.

[6] Gang, Wenjie, et al. "Impacts of cooling load calculation uncertainties on the design optimization of building cooling systems." Energy \& Buildings 94(2015):1-9.

[7] Chen, Jianli, et al. "Uncertainty Analysis of Thermal Comfort in a Prototypical Naturally Ventilated Office Building and Its Implications Compared to Deterministic Simulation." Energy \& Buildings 146(2017).

[8] Domínguez-Muñoz, Fernando, J. M. Cejudo-López, and A. Carrillo-Andrés. "Uncertainty in peak cooling load calculations." Energy \& Buildings 42.7(2010):1010-1018. 